NBER WORKING PAPER SERIES

\title{
THE IMPACT OF CHILDREN'S PUBLIC HEALTH INSURANCE EXPANSIONS ON EDUCATIONAL OUTCOMES
}

\author{
Phillip B. Levine \\ Diane Whitmore Schanzenbach \\ Working Paper 14671 \\ http://www.nber.org/papers/w14671
NATIONAL BUREAU OF ECONOMIC RESEARCH
1050 Massachusetts Avenue
Cambridge, MA 02138
January 2009

We are grateful for helpful comments from Amy Finkelstein, Dana Goldman, Larry Hedges, Helen Levy and an anonymous referee along with participants at a seminar at the University of Illinois at Chicago and the Frontiers in Health Policy Research Conference. We also are grateful to Jennifer Humensky, Lindsey Leininger and Elizabeth Munnich for helpful research assistance. We also gratefully acknowledge funding from the U.S. Department of Education under grant \#R902B050006. The views expressed herein are those of the author(s) and do not necessarily reflect the views of the National Bureau of Economic Research.

NBER working papers are circulated for discussion and comment purposes. They have not been peerreviewed or been subject to the review by the NBER Board of Directors that accompanies official NBER publications.

(C) 2009 by Phillip B. Levine and Diane Whitmore Schanzenbach. All rights reserved. Short sections of text, not to exceed two paragraphs, may be quoted without explicit permission provided that full credit, including $(\subset$ notice, is given to the source. 
The Impact of Children's Public Health Insurance Expansions on Educational Outcomes Phillip B. Levine and Diane Whitmore Schanzenbach

NBER Working Paper No. 14671

January 2009

JEL No. I18,I21

\begin{abstract}
$\underline{\text { ABSTRACT }}$
This paper examines the impact of public health insurance expansions through both Medicaid and SCHIP on children's educational outcomes, measured by 4th and 8th grade reading and math test scores, available from the National Assessment of Educational Progress (NAEP). We use a triple difference estimation strategy, taking advantage of the cross-state variation over time and across ages in children's health insurance eligibility. Using this approach, we find that test scores in reading, but not math, increased for those children affected at birth by increased health insurance eligibility. A 50 percentage point increase in eligibility is found to increase reading test scores by 0.09 standard deviations. We also examine whether the improvements in educational outcomes can be at least partially attributed to improvements in health status itself. First, we provide further evidence that increases in eligibility are linked to improvements in health status at birth. Second, we show that better health status at birth (measured by rates of low birth-weight and infant mortality), is linked to improved educational outcomes. Although the methods used to support this last finding do not completely eliminate potentially confounding factors, we believe it is strongly suggestive that improving children's health will improve their classroom performance.
\end{abstract}

\author{
Phillip B. Levine \\ Department of Economics \\ Wellesley College \\ Wellesley, MA 02481 \\ and NBER \\ plevine@wellesley.edu \\ Diane Whitmore Schanzenbach \\ Harris School \\ University of Chicago \\ 1155 E. 60th Street Suite 143 \\ Chicago, IL 60637 \\ schanzenbach@uchicago.edu
}




\section{INTRODUCTION}

The main goal of expanding access to health insurance is to improve the health of the population. The most recent policy interventions designed to address that goal were expansions to the Medicaid system and the introduction of the State Children's Health Insurance Program (SCHIP). These policies made available public health insurance coverage to children from families with incomes that previously would have been too high to qualify. Despite evidence of some crowd-out of private health insurance coverage, they have been shown to improve children's health status, as reviewed below.

Yet the benefits associated with increased public health insurance coverage may extend beyond improvements in health status. In particular, one could imagine that these interventions may improve educational outcomes. Two potential mechanisms could generate such a result. First, children in poor health may be poorly equipped to learn; alleviating their health problems could remove barriers that would enable them to succeed in the classroom. ${ }^{1}$ Second, educational outcomes may improve even if crowd-out dampens the health impact. Families that switch from private to public health insurance would have additional resources that may be devoted towards human capital development.

The goal of this paper is to address this issue, examining the impact of public health insurance expansions (through both Medicaid and SCHIP) on children's educational outcomes. In our analysis, we examine the health-related determinants of educational performance,

\footnotetext{
${ }^{1}$ The policy community has been clear in its recognition of the problem. For instance, the U.S. Department of Education has provided a review of the factors that hinder student achievement with the goal towards finding ways to promote academic success (Rossi and Montgomery, 2004). The review states that "poor health and untreated physical conditions may slow a child's academic progress. Recurrent illness, for example, may interfere with attentiveness and attendance, and vision or hearing problems may make class participation difficult." The National Governors Association is also promoting interventions to improve children's health as a mechanism to improve academic performance (National Governors Association, 2000).
} 
measured by test scores in reading in math at ages 9 and 13, available from the National Assessment of Educational Progress (NAEP). We begin our analysis relying on the cross-state variation over time and across ages in children's health insurance eligibility brought about by the Medicaid expansions and the introduction of SCHIP. The availability of test scores at different ages in the same year provides the opportunity to implement a triple-difference estimation strategy. Using this approach, we find evidence that test scores in reading, but not math, increased for those children affected at birth by the increase in health insurance eligibility.

We go on to examine the potential mechanism for this effect. Specifically, we seek to determine whether the improvements in educational outcomes can be attributed to improvements in health status itself. First, we provide further evidence that increases in eligibility are linked to improvements in health status at birth. In states/years in which public health insurance was more broadly available, the rate of births with low birth-weight declines. This effect is larger for lesseducated mothers, as one would expect based on eligibility rules. Second, we go on to show that better health status at birth, as measured by rates of low birth-weight and infant mortality, is linked to improved educational outcomes. Although this last finding is based on a methodology that does not completely eliminate potentially confounding factors, we believe it is strongly suggestive that improving children's health will improve their performance in the classroom.

\section{LITERATURE REVIEW}

There is an extensive clinical literature relating poor child health to worse cognitive and behavioral outcomes. Children with chronic conditions, like asthma, have been found to be more likely to repeat a grade and are more poorly behaved (Gortmaker, et al. 1990). Children with chronic conditions that are not well treated are especially at risk. For example, Diette, et al. 
(2000) find that children with asthma that is not well-controlled are more likely to miss school.

Fowler et al. (1992) find that asthma is associated with more grade retention; this relationship is stronger among children from low-income families than high-income families. Gozal (1998) finds that children who are treated for sleep apnea improve their school performance after treatment. Children with ADHD are more likely to be retained or drop out, have lower grades and exhibit worse behavior (Barkley 2002). ${ }^{2}$ This literature, however, is plagued by the inability to distinguish causal mechanisms from mere associations.

An alternative strand of the literature focuses on the relationship between health care and well-being using strategies better-suited for identifying causal effects. In their review of the evidence on the causal impact of health insurance coverage, Levy and Meltzer (2008, p. 406) conclude that "the evidence available to date conclusively demonstrates that health insurance improves the health of vulnerable subpopulations" such as infants and children.

Past research has also focused on the impact of the expansion of the Medicaid system, as we do, finding that it led to improved health outcomes for children. Currie and Gruber (1996b) find that it improved mothers' prenatal care, substantially reducing infant mortality and the incidence of low birth weight. Currie and Gruber (1996a) find that Medicaid expansions reduced child mortality by over 5 percent. $^{3}$ Dafny and Gruber (2005) find that increased Medicaid eligibility reduced the incidence of avoidable hospitalizations, which have apparently been prevented by more appropriate care through an early contact with a primary care physician.

\footnotetext{
${ }^{2}$ Currie \& Stabile (2006) provide evidence that ADHD symptoms decrease school achievement and attainment within the context of a sibling difference model, which is more indicative of a causal effect.

${ }^{3}$ This reduction in child mortality may actually lead to a reduction in test scores if the marginal children who are born are lower than average performers on standardized tests. Any improvement in test scores that we are able to attribute to increased health insurance coverage is actually net of this effect. The practical implications of this issue may be rather limited, however, because infant mortality rates are so low (in the vicinity of 1 percent over the sample period) that a five percent reduction in infant mortality means that these marginal children will only increase the size of the birth cohort by an additional .05 percent of children born.
} 
Some evidence also shows that the more recently introduced SCHIP program has led to improved health outcomes for children. LoSasso and Buchmueller (2004) show that SCHIP is associated with an increase in health insurance coverage among the eligible, uninsured population. Joyce and Racine (2003) find that SCHIP increases the probability that a child receives a newly approved vaccine. We also provide additional evidence later in this paper that eligibility expansions improved children's health.

Although public insurance expansions were primarily designed to cover the uninsured, one possible response is for individuals to give up their private insurance coverage and replace it with less expensive public coverage. This is a phenomenon known in the literature as "crowdout," and a considerable body of research has documented its existence (Cutler and Gruber 1996, 1997; Dubay and Kenney 1996, 1997; Blumberg, Dubay and Norton 2000; Yazici and Kaestner 2000; Shore-Sheppard 2005; Ham and Shore-Sheppard 2005; and Gruber and Simon, 2008). There is no evidence to suggest, however, that crowd-out is complete, so the expansions in health insurance access did increase actual insurance coverage for at least some children. Past research has also focused on the impact of crowd-out on household spending under the theory that crowdout will free up some resources previously spent on insurance coverage for children. Gruber and Yelowitz (1999) find that households targeted by the Medicaid expansions of the late 1980s and early 1990s significantly increased their spending in other areas. In the end, the literature on the impact of recent public health insurance expansions indicates that children's health did improve, but crowd-out occurred as well. As we described earlier, both effects may have been at work improving educational performance; examining this relationship is the focus of this paper.

Past research also provides evidence on the role of family resources on children's educational outcomes. Much of this literature, reviewed by Haveman and Wolfe (1995) and 
Mayer (1997), relies on correlational analysis and fails to isolate the causal effect of family resources on child outcomes. Two recent additions, however, effectively isolate the causal effects. Morris, Duncan and Rodrigues (2004) combine evidence from several randomly assigned welfare reform demonstrations and are able to separate the effect of increases in income from the other aspects of treatment. They find that a $\$ 1,000$ increase in family income improves child test scores by 6 percent of a standard deviation. Dahl and Lochner (2005) use expansions in the Earned Income Tax Credit to isolate the effect of changes in income on child test scores. They find that a $\$ 1,000$ increase in family income improves child reading scores by 3.6 percent of a standard deviation, and math scores by 2.1 percent.

Currie (2008) provides a comprehensive review of the role that children's health status plays in determining subsequent socioeconomic outcomes, including education. Her main conclusion is that "in developed countries, there has been relatively little examination of the question of whether poor health in childhood is linked to lower future socioeconomic status (p. 26)." Much of the literature that exists is plagued by difficulties in identifying causality, relying on correlations instead. Case, Fertig and Paxson (2005) use unusually rich panel data from Great Britain and find that, after controlling for family background characteristics, unhealthy children attain less schooling. Although this is an important finding, issues of unobservable heterogeneity remain. Bleakley (2007) finds that the health improvements induced by the eradication of hookworm - which infected a large proportion of Southern school-aged children around 1910 - led to increased school attendance and literacy. This study has the advantage of a strong identification strategy, but its relevance to modern-day changes in health status is questionable. 
One area in which credible methodologies have been applied to related questions is the relationship between low birth weight and later educational outcomes. Several studies have measured differences in educational outcomes between siblings/twins associated with differences in their birth weight (cf. Conley and Bennett, 2000; Behrman and Rosenzweig, 2001; Boardman

et al., 2002; and Black, Devereux and Salvanes, 2007). All find that low birth weight leads to poorer academic performance, usually measured as total years of education attained.

\section{MEDICAID EXPANSIONS AND SCHIP}

Part of our research design focuses on the variation in public health insurance eligibility that is associated with the expansions of the Medicaid system in the late 1980s and early 1990s and the introduction of the State Children's Health Insurance Program (SCHIP) in the late 1990s. In this section, we review the institutional arrangements that generate this policy variability.

The Medicaid system is the main government program that provides health insurance to the poor. Prior to 1984, eligibility for Medicaid among those who were not elderly or disabled was strongly tied to eligibility for Aid to Families with Dependent Children (AFDC). Between 1984 and 1992, eligibility was decoupled from AFDC and was widely expanded - first to pregnant women through 1987, and then after that to poor families with income levels that had previously been too high to qualify for the program, up to 185 percent of the poverty line. These policy changes led to a dramatic increase in the fraction of children who were eligible for Medicaid; the percentage of children 0 to 15 eligible more than doubled, from about 14 percent to about 31 percent between 1983 and 1996 (Gruber, 2003). The SCHIP program, introduced in 1997, allowed states to expand eligibility to older children and to further raise income eligibility thresholds. 
Table 1 details the differences in children's health insurance eligibility as a result of the Medicaid expansions and the introduction of SCHIP between 1988 and 2004 and between states for the five most populous states. Over time, each state (generally) increased the income threshold under which children could qualify for Medicaid. These thresholds tended to begin at the poverty line in the late 1980s and more recently have crept up to two or three times that. In the late 1980s, only infants in these low-income households were eligible, but the maximum age that would enable one to qualify for benefits has also risen over time so that children meeting the (now higher) income thresholds are eligible for benefits through the end of their teen years. Both of these types of changes occurred at different rates in different states.

Because of the differences in timing and generosity, otherwise similar children residing in different states may have been treated differently by the Medicaid system measured at a point in time or cumulatively over their entire lives. Table 2 presents an example of this, documenting these differences for children who continuously reside in the five largest states, who were born in 1986, 1988, and 1990, and whose family income was at 120 percent of the poverty level in each

year since birth. The results of this simulation exercise show the wide variety of health insurance exposure that these children face. Lifetime exposure varies between 1 and 7 years by age 9 and between 2 and 11 years by age 13. Some children are covered at birth. Children born in different states at the same time and children born within a state at different times all had differential exposure to public health insurance.

\section{METHODOLOGY}

In our analysis, we begin by focusing on the reduced form impact of access to public health insurance on educational outcomes. We then recognize that this impact may be generated 
either by improvements in health status or through the additional income generated if the availability of public health insurance crowds out privately purchased health insurance. We subsequently attempt to determine whether we can identify a direct impact of the health improvements itself.

All of this can be characterized by the following structural model of educational outcomes:

$$
\begin{gathered}
E_{i s t}=\delta_{0}+\delta_{1} H_{i s t}+\delta_{2} I_{i s t}+\delta_{3} X_{i s t}+\varepsilon_{i s t} \\
H_{i s t}=\gamma_{0}+\gamma_{1} P H I_{s t}+\gamma_{2} X_{i s t}+u_{i s t} \\
I_{i s t}=\lambda_{0}+\lambda_{1} P H I_{s t}+\lambda_{2} X_{i s t}+v_{i s t}
\end{gathered}
$$

where $\mathrm{E}_{\text {ist }}$ represents some measure of educational performance for individual $\mathrm{i}$ in state $\mathrm{s}$ at time t, $H_{\text {ist }}$ represents the child's health status, $I_{\text {ist }}$ represents the child's family income, $X_{\text {ist }}$ is a composite variable that represents other individual-specific factors that are related to school outcomes, $\mathrm{PHI}_{\mathrm{st}}$ represents provisions of the state's public health insurance policies for lower income children, which depends upon the particular year and the child's state of residence, and $\varepsilon_{i s t}, u_{i s t}$, and $v_{i s t}$ represent random error terms. The reduced for specification of this structural model would take the form:

$$
E_{i s t}=\beta_{0}+\beta_{1} P H I_{s t}+\beta_{2} X_{i s t}+v_{i s t}
$$

In this model the coefficient, $\beta_{1}$, represents the impact on educational performance associated with a child's exposure to public health insurance eligibility.

We begin our analysis by estimating equation (4) to determine whether we are able to find any reduced form effect. In practice, we augment this model (and all subsequent models) with state fixed effects (to control for longstanding differences across states in things like willingness to fund social programs and other underlying cultural differences) and year fixed 
effects (to control for arbitrary movements in educational outcomes over time that occur in all states simultaneously). This approach represents a differences-in-differences estimator of the impact of public health insurance on educational outcomes. Difference-in-difference models suffer from the imperfection that time varying factors within states - such as state-level accountability policies or abrupt changes in school funding levels - cannot be captured by state or year fixed effects. If these time-varying, state-specific factors are correlated to both health insurance eligibility and educational outcomes, then they may introduce bias. ${ }^{4}$ To circumvent this problem, we use the fact that tests are given to children in different grades within state and year, but the children in different grades were subject to different health insurance eligibility rules. This provides a third difference, allowing us to sweep out the effects of state-by-time specific effects.

One limitation of this analysis is that it is impossible to determine whether any estimated impact of public health insurance access on education performance in equation (4) can be specifically attributable to the health or the income channel. This can easily be seen based on equations (1) through (3). If another variable were available that we could relate to health status or income, we could identify the specific mechanism, but we are unable to identify any such variable.

As it stands, we focus on trying to determine whether health status plays a role in the reduced form relationship. To do this, we first estimate a model similar in form to equation (2), attempting to provide further evidence on the relationship between public health insurance and improvements in children's health. Past research has extensively addressed this issue and found

\footnotetext{
${ }^{4}$ Researchers also worry about "policy endogeneity," where state policies respond to the outcome being examined. In the present context, however, it seems unlikely that states would enact legislation enacting health care in response to the latest state test score results.
} 
such a link, as described earlier. Our contribution is to use a longer panel, combining the Medicaid expansions and the introduction of SCHIP, providing more power to the analysis.

Second, we estimate a model similar in spirit to that in equation (1), but focusing on the relationship between educational outcomes and measures of children's health status at birth. ${ }^{5}$ An important caveat in this analysis is that it is difficult to attribute causality in the relationship between children's health status and educational outcomes as estimated in models like this. It could be the case that other underlying social conditions, either at the time the test scores were measured, or at the time of the children's birth, were changing within the state that would generate a spurious relationship between test scores and health. One should note that these problems may be attenuated because we also compare differences in test scores between $4^{\text {th }}$ and $8^{\text {th }}$ graders as a function of differences in health status at birth since both groups would be exposed to many of the same contemporaneous factors. Taking these differences would eliminate the bias introduced by the presence of such factors. Nevertheless changes in underlying social conditions in the state that differentially affected the different birth cohorts could still introduce bias.

\section{DATA DESCRIPTION}

The two main variables represented in our empirical specification are the measures of educational performance and the measures of public health insurance eligibility. In this section of the paper we will detail our sources, properties, and creation of these variables along with the remaining data used in our analysis.

\footnotetext{
${ }^{5}$ In theory, we could also include "income" as in equation 1, but measured income would not capture the additional resources available to the family through public provision of child health insurance. Expenditures would better capture that concept, but no such data are available.
} 
The measures of educational performance that we use are test scores in reading and math from the National Assessment of Educational Progress (NAEP), which is sometimes referred to as the "nation's report card." Exams are administered periodically to students in $4^{\text {th }}$ and $8^{\text {th }}$ grades to a nationally representative sample of students. Beginning in 1990, states began to augment the national samples to create samples of students that were representative of their own populations. $^{6}$ Not all states participated in the early years, so our resulting data panel is unbalanced. Tests in reading and math are the ones most commonly conducted and we will restrict our attention to them. ${ }^{7}$ We use state-level average scaled scores (separately by grade), which range between 0 and 500 .

NAEP also collects information on a student's demographic characteristics, including race/ethnicity, parental education level, and free lunch status, allowing us to calculate average scores for various subgroups. The use of free lunch status would be of particular value in providing a potential third difference since those receiving free or reduced price lunches should be more likely to be subject to the expanded eligibility standards. Unfortunately, free lunch data are only available beginning in 2000 , restricting our sample size to such an extent that we were unable to obtain precise parameter estimates in such models. Results across other subgroups were not significantly different, so we do not report those results below but they are available upon request.

To measure the generosity of public health insurance, we follow Currie and Gruber (1996a) and employ a "simulated instrument" approach. In this approach, we begin with a nationwide sample of children from the Current Population Survey and determine whether or not

\footnotetext{
${ }^{6}$ The number of test takers within each state is roughly comparable across states. This means that regression models that rely on cross-state variation over time do not need to be weighted by state population.

${ }^{7}$ Math scores are available for $4^{\text {th }}$ grade in $1992,1996,2000,2003$, and 2005 and for $8^{\text {th }}$ grade in $1990,1992,1996$, 2003, and 2005. Reading scores are available for $4^{\text {th }}$ grade in $1992,1994,1998,2002,2003$, and 2005 and for $8^{\text {th }}$ grade in 1998, 2002, 2003, and 2005.
} 
they would be eligible for coverage under the rules in each state/year based on the child's age and family income. ${ }^{8}$ Since the sample is national in scope, and not state-specific, this approach provides a measure of the generosity of a state's plan, but abstracts from differences in populations across states. We can apply this approach directly to determine measures of contemporaneous eligibility rates in each state and in each year. We can also make an additional assumption that the family's income remained roughly constant and that the child lived in the same state since the child's birth to construct a measure of lifetime public health insurance eligibility, much like we did in Table 2. ${ }^{9}$ If we run our national sample of children through each state's eligibility rules since the child was born, we can construct measures of exposure to public health insurance for each state and birth cohort. Finally, we can use a similar approach to determine eligibility rates in the year the child was born.

To create these simulated instruments, we use data from the March Current Population Surveys (CPS). The March CPS provides data on family income in the preceding calendar year for a national sample of roughly 100,000 individuals each year. We can select children from these data, attach their families' income to them, and then run them through a program that would identify their simulated health insurance eligibility at birth, in the years since birth, and at present depending upon when they were born.

Figure 1A displays trends in measures of children's health insurance eligibility over the last couple of decades. Prior to the expansion of the Medicaid system in the mid 1980s, roughly 16 percent of newborns and 10 percent of 9 and 13 year olds were covered, typically because

\footnotetext{
${ }^{8}$ These rules were obtained from Yelowitz (1995), Shore-Sheppard (2002), and CMMS (2004).

${ }^{9}$ A preliminary analysis of data from the National Longitudinal Survey of Youth shows that about 85 percent of children live in the same state at age 14 as their state of birth. Similarly, the correlation between their family's income by age 3 with their income between ages 10 and 14 was 44 percent. This estimate is almost certainly an understatement, attributable to measurement error in reported family income (cf. Zimmerman, 1992; and Solon, 1992).
} 
their family was receiving AFDC benefits. Eligibility among very young children (newborns in this figure) started to rise in the late 1980s and then for somewhat older children ( 9 year olds in this figure) in the early 1990s, and finally for older children (13 year olds in this figure) starting in the mid 1990s. By 2003, we find that over 50 percent of all newborns and over 40 percent of 9 and 13 year olds are eligible for public health insurance.

The change in eligibility associated solely with the income-based Medicaid expansions is depicted in Figure 1B. This is an important figure because the key explanatory variables in our regression models reflect Medicaid eligibility solely attributable to the income-based expansions. ${ }^{10}$ In this figure, eligibility is set at zero prior to 1987 because eligibility was still tied to the income thresholds associated with welfare. It was beginning in that year and initially for infants that income thresholds for eligibility began to rise. Within a couple of years, about onethird of all newborns were eligible for Medicaid. For nine year olds, the improved access to coverage began in earnest in 1992; by 1992 about one-quarter of children at this age were eligible. The process was a bit more gradual for 13 year olds, as eligibility rose from a negligible level to about one-quarter of 13 year old children by 1996. For children of all ages the expansion of eligibility brought about by SCHIP continued the escalation of eligibility through the end of our sample period.

Figures 2 and 3 depict the nature of the variation in public health insurance eligibility that we are able to exploit in our econometric analysis. In each figure, the y-axis measures the standard deviation in eligibility rates across states and the $\mathrm{x}$-axis measures the year in which the test is taken; $4^{\text {th }}$ graders and $8^{\text {th }}$ graders are compared separately. The figures are distinguished by eligibility at birth (Figure 2) and contemporaneous eligibility (Figure 3). Figure 2 shows that

\footnotetext{
${ }^{10}$ The reason for this is because of the difficulty of projecting backwards an individual's family structure based on contemporaneous data, which is all the information that we have available.
} 
the variation across states in rates of eligibility at birth began in 1996 among $4^{\text {th }}$ graders (age 9) and in 2000 for $8^{\text {th }}$ graders (age 13), which is consistent with the initial introduction of these state options in 1987. ${ }^{11}$ The extent of that variation increased considerably once this process began to spread across the states. An important lesson from this figure is that there is considerable variability in the time series patterns between $4^{\text {th }}$ and $8^{\text {th }}$ graders. For those currently eligible, we see that the variation across states was greatest in the period just prior to SCHIP in 1997, particularly for the 13 year olds. When SCHIP went into effect, it reduced disparities in eligibility among older children. Those disparities were greatest in the years preceding it as states were allowed to offer eligibility to older children, but weren't required to. This is the nature of the variability that we exploit in our subsequent empirical analysis.

In addition to our two main data sources, we also use additional data from the Vital Statistics system as well as other CPS data. In specifications where we consider specific children's health outcomes, we take advantage of Vital Statistics data on infant mortality and low birth weight. We use additional data from the CPS to construct measures of the demographic features of a state's population over time (used as explanatory variables in our regressions) to help control for some of the time-varying covariates within a state. Each month, one quarter of the CPS sample exits the survey; data for members of these "outgoing rotation groups" over the course of a full year are available and the use of these data provides a sample size three times the size of any single survey. We use these data to measure demographic characteristics, including age, race, marital status, and educational attainment. Our final source of data is state level data on the unemployment rate, which is available from the Bureau of Labor Statistics.

\footnotetext{
${ }^{11}$ The variation across states in eligibility at birth increased again in 2001 among $4^{\text {th }}$ graders and 2005 among $8^{\text {th }}$ graders. The reason for this is that most states standardized their eligibility cutoffs for young children, including newborns, at 133 percent of the poverty line in 1991, but then states began getting more generous after that, with some states expanding coverage to young children up to $300 \%$ of the poverty line.
} 


\section{RESULTS}

To begin our empirical analysis, we first report the results of estimating models of the form of equation (4), which reflects the reduced form relationship between test scores in different subjects/grades as a function of public health insurance eligibility at birth, since birth, and contemporaneously. We also report results from a "triple differences" estimating strategy, comparing results between $4^{\text {th }}$ and $8^{\text {th }}$ graders as a function of differential exposure to our three measures of public health insurance eligibility.

Results from these reduced form specifications are reported in Table 3. These specifications include three different measures of exposure to public health insurance: the percentage eligible in a student's year of birth, the percentage of life eligible since birth, and the percentage currently eligible. In this specification, the variability in the percentage of life eligible since birth is identified based on variability in eligibility in the years following birth and prior to the current year. For instance, at age 9 this variable is identified based on variability in eligibility in years 1 through 8 of the student's life. ${ }^{12}$

The results in Table 3 indicate that we are unable to detect an impact of any of our health insurance measures on reading test scores separately in $4^{\text {th }}$ or $8^{\text {th }}$ grades. When we introduce the third difference and compare results for $4^{\text {th }}$ and $8^{\text {th }}$ graders (in effect sweeping out state-by-time fixed effects) and relate that difference to differences in public health insurance exposure, however, we find a positive and statistically significant relationship between eligibility at birth

\footnotetext{
12 Each of these measures of eligibility can have different effects on current test scores because there is no reason to expect that the impact of health insurance eligibility should be linear over a child's life. In fact, since health problems at birth are so much more common than health problems subsequent to birth, one might anticipate that reducing the health problems at birth would have a larger effect on subsequent life outcomes. Currie, Decker, and Lin (2008) find a result consistent with this fact. In their work, they find that Medicaid eligibility at very young ages has a positive impact on future health status despite the fact that current Medicaid eligibility is not found to have an impact.
} 
and reading scores (Column 3). ${ }^{13}$ This pattern of results suggests that contemporaneous factors affecting both $4^{\text {th }}$ and $8^{\text {th }}$ graders are introducing a bias that the triple difference strategy can resolve. We are unable to detect any impact on math test scores in $4^{\text {th }}$ grade, $8^{\text {th }}$ grade, or in the difference between grades in response to any of the measures of public health insurance eligibility.

The results for reading test scores support the notion that expanding access to public health insurance may improve educational performance. The estimated magnitude of this effect is relatively small. A 50 percentage point increase in public health insurance eligibility at birth is estimated to increase reading test scores by 3 scaled points (or 0.091 standard deviation) on a base of about 239 (the mean of the $4^{\text {th }}$ and $8^{\text {th }}$ grade mean scaled scores). Of course, improvements in reading scores are only one of the potential benefits of health insurance expansions. ${ }^{14}$

Although these results are informative, the reduced form nature of this analysis prevents us from identifying the mechanisms at work in generating test score gains. As we have previously described, this finding could be attributable to improvements in health outcomes or the increased family resources available to the extent that crowd out occurs (or some combination of the two). In the remainder of this discussion, we attempt to determine whether we can identify specifically the role that health improvements may play. We focus our attention on health status at birth since insurance access at births appears to be driving the improvement in reading test scores. We use rates of low birth weight and infant mortality as our measures of

\footnotetext{
${ }^{13}$ Results for eligibility at birth are quite similar if we omit controls for contemporaneous and lifetime eligibility.

${ }^{14} \mathrm{We}$ attempted one extension of this analysis directed at identifying whether the estimated impact of the expansions differed by time period. This could occur if, for instance, the impact differed at different levels of the income distribution since the system's expansion over time affected different portions of the income distribution. Unfortunately, the limitations of the NAEP data made such an exercise too weak to be useful. Because the data exist for sporadic years and are not consistent between tests at different grades, the sample size is significantly limited when we try to separate out early and later years for the analysis, particularly in the triple difference models.
} 
children's health. This is not to say that these are the only channels through which public health insurance can improve children's health, but these are two measures for which data are available on the scale necessary to conduct this exercise. We see them as markers of children's health status that may capture part, but by no means all, of the improvement in health associated with access to health insurance.

Our first approach is to provide additional evidence that increased public health insurance access at birth has an impact on children's health status. Methodologically, we estimate models that take the general form of equation (2), augmenting this statistical model with state and year fixed effects along with state-specific linear trends. ${ }^{15}$ These regressions are comparable to those used in past work, like Currie and Gruber (1996a and 1996b) and Joyce and Racine (2003). The contribution here is that we expand the time period covered to encompass both the earlier period of Medicaid expansions along with the more recent introduction and implementation of SCHIP to get a broader picture of the role that public health insurance has played in affecting children's health status.

In these regressions, we estimate models aggregated to births to all mothers and separately for mothers who differ by their level of educational attainment. Since public health insurance expansions should be more likely to affect less educated mothers, we should observe estimated effects that are greater for those groups. When we conduct our analysis using infant mortality rates by mothers' level of education, our sample is restricted because linked natality and infant death records are only currently available for 1984-1991 and 1995-2001. These linked records are necessary to attach the mother's level of education to the child's death. We use data from 1984-2003 in the remainder of the analysis. In these specifications, all regressions

\footnotetext{
${ }^{15} \mathrm{We}$ are able to use state-specific linear trends in this part of our analysis because of the longer time series of data available within each state. In our analysis using the NAEP data, there are too few observations within states to yield robust results when we include state-specific trends.
} 
are weighted by the number of births in the state/year to help resolve issues of heteroskedasticity that arise from the different sample sizes in each state. Here (and elsewhere) standard errors are clustered at the state level to correct for arbitrary covariance structures over time within states.

The results of this analysis are reported in Table 4. The top panel provides results from models in which the dependent variable is the rate of low birth weight. For children as a whole, 7.3 percent of children are born weighing less than $2500 \mathrm{~kg}$ (the cut-off for a determination of low birth weight). This rate varies with mother's level of education, ranging from 9.2 percent for children of mothers who are high school dropouts to 5.6 percent for children of mothers who graduated from college. The results indicate that greater health insurance eligibility reduces the rate of low birth weight children for women as a whole. ${ }^{16}$ They also indicate that the estimated impact of greater public health insurance eligibility declines as a mother's education increases, as one would predict since more highly educated women are less likely to qualify for public health insurance.

To gauge the magnitude of the estimated impact, note that the percentage of children eligible for public health insurance at birth solely attributable to the income-based Medicaid expansions rose by about 40 percentage points between the mid 1980s and mid 1990s (i.e. just prior to the introduction of SCHIP). Based on our estimates for all women (coefficient of about 0.3 ), this implies a 0.12 percentage point reduction in the rate of low birth weight in response to the expansions to public health insurance eligibility among children. With a base rate of 7.3 percent, this reflects a modest 1.6 percent reduction.

\footnotetext{
${ }^{16}$ Although earlier Medicaid expansions clearly included prenatal care, the coverage of prenatal care in the SCHIP expansions is less clear. We estimated our low birth weight regressions separately for the two periods (1996 and earlier compared to post-1996) and find that the results reported here are largely driven by those from the Medicaid expansion period.
} 
We also find some evidence of a small effect when we examine the impact on infant mortality. When we focus our analysis on births to women with a high school degree, a group likely to be affected by the policy change, we see a marginally statistically significant reduction in infant mortality associated with an increase in public health insurance eligibility. Again, the magnitude of these estimates is modest. The mean infant mortality rate is 0.867 per 1000 births to women with a high school degree. If there is a 40 percentage point increase in public health insurance eligibility among children at birth, this rate would decline by 0.058 per 1000 births, or 6.7 percent among women with a high school degree who gave birth. The impact on infant mortality more broadly would be smaller than that.

We can conclude from this analysis that the expansion of public health insurance does appear to have improved the health status of children. The magnitudes of the impact on low birth weight and infant mortality are not large, but these individual measures of children's health may not completely capture the true impact on the well-being of children in ways that would affect their educational attainment. Unfortunately, data limitations prevent us from testing other measures of health status. The fact that we are able to detect impacts on children's health using these broad measures suggest that other aspects of health may have been improved as well in ways that could affect educational outcomes.

We move on to consider the direct relationship between child health and test score outcomes, as represented by equation (1) augmented by state and year fixed effects. As before, our measures of educational outcomes are test scores in reading and math in $4^{\text {th }}$ and $8^{\text {th }}$ grades, and children's health status is proxied by the infant mortality rate and the rate of low birth weight in the year the children were born. As noted above, it is difficult to attribute causality in a model like this, because if other underlying social conditions were changing - either at the time the test 
scores were measured, or at the time of the children's birth - within the state, that would generate a spurious relationship between test scores and health. Although the triple-difference approach alleviates this problem somewhat if both the $4^{\text {th }}$ and $8^{\text {th }}$ graders were exposed to many of the same contemporaneous factors, nonetheless changes in underlying social conditions in the state that differentially affected the different birth cohorts could still introduce bias.

The results of this analysis are reported in Table $5 .{ }^{17}$ Among both $4^{\text {th }}$ and $8^{\text {th }}$ grade students we are unable to see a consistent pattern in the relationship between health status at birth and test scores. Higher infant mortality rates in the student's year of birth are estimated to significantly reduce math scores in $4^{\text {th }}$ grade and reading scores in both grades, but rates of low birth weight are not found to be significantly associated with test scores in either grade. Columns 3 and 6 repeat this analysis, but focusing on the difference in test scores between cohorts in relation to the difference in health status in birth. Here we see a consistent relationship that cohorts born in worse health, measured by infant mortality and low birth weight, appear to perform worse on reading tests. With a mean infant mortality rate in our sample of 0.9 (per 1000 births) and a mean rate of low birth weight of 8 (per 100 births), these estimates are not very large. A 4 percentage point increase in the rate of low birth weight - that is, a 50 percent increase in the rate - would decrease reading test scores by about 4 points (or 0.12 standard deviation) on a base value of 238.7 pooled across the $4^{\text {th }}$ and $8^{\text {th }}$ grade mean scores.

\footnotetext{
${ }^{17}$ The analysis reported in Tables 4 and 5 can be thought of like a first stage and a structural equation in a two-stage least squares model for which instrumental variables may be considered a viable estimation strategy. We have chosen not to go down that path for two reasons. First, the "first stage" regressions in Table 4 take advantage of the maximum amount of Vital Statistics data available. The test score models in Table 5 are estimated using a restricted set of state/year cells based on NAEP data availability. If we estimate the first stage regressions on this limited number of cells, we lose sufficient power that nothing is statistically significant, so estimating a formal IV model would provide a very weak test. Second, this IV model would suggest that the only avenue that Medicaid expansions would alter educational outcomes would be through low birth weight or infant mortality. Those two health outcomes are used in this analysis as markers of health conditions that may be affected by Medicaid expansions, but are not meant to be the exclusive mechanisms.
} 
Put into a different context, the nationwide rate of low birth weight births increased by 0.8 points (from 6.8 to 7.6 per 100) from 1980 to 2000 . An increase of this magnitude would imply a mean reading test score decline of 0.025 standard deviations. Similarly, a health improvement associated with a 0.5 increase in the infant mortality rate would reduce reading test scores by 2.4 points (or 0.07 standard deviation).

\section{CONCLUSIONS}

The results of our analysis suggest that children's greater access to public health insurance at birth improved their performance on standardized tests of reading ability. We then focused our analysis at determining whether we could find evidence that this effect was generated by actual improvements in children's health associated with the expanded access as opposed to (or at least in addition to) greater resources available to families through crowd out of private insurance. We found additional evidence supporting the relationship between insurance eligibility and infant health outcomes. Our findings in this regard augment past research that has also obtained this result. In addition, we were also able to directly link infant health outcomes, in the form of low birth weight and infant mortality, to reading test scores. This evidence expands upon previous research that has found low birth weight to be negatively related to educational outcomes. Although our findings in this part of the analysis are subject to methodological limitations, combined with the past literature we believe that they provide meaningful evidence of a link between infant health and test scores. Taken as a whole, we find that the improvement in reading test scores associated with children's public health insurance expansions is at least partially attributable to direct improvements in children's health. 
One interesting aspect of our findings is that we are only to identify a relationship between children's health at birth and reading test scores, but not math test scores. Why would one set of scores be affected, but not the other? Jacob (2005) proposes a potential explanation imbedded in a statement he made regarding the results of an accountability study he conducted: "This is consistent with a number of education evaluations that show larger effects in math than reading, presumably because reading achievement is determined by a host of family and other non-school factors while math achievement is determined largely by school (p. 771)." If this viewpoint is correct, then it is likely that health improvements would fall into the category of family and non-school factors that are more likely to affect reading scores. 


\section{REFERENCES}

Barkley, Russell A. 2002. "Major Life Activity and Health Outcomes Associated with Attention-Deficit/Hyperactivity Disorer." Journal of Clinical Psychiatry. 63[suppl 12]10-15.

Behrman, Jere and Mark R. Rosenzweig. 2001. "The Returns to Increasing Body Weight." Penn Institute for Economic Research Working Paper 01-052.

Black, Sandra, Paul Devereux and Kjell Salvanes. 2007. "From the Cradle to the Labor Market? The Effect of Birth Weight on Adult Outcomes.” Quarterly Journal of Economics, 122:1.

Bleakley, Hoyt. 2007. "Disease and Development: Evidence from Hookworm Eradication in the American South." Quarterly Journal of Economics, 122:1.

Blumberg, Linda J., Lisa Dubay, and Stephen A.Norton. 2000. "Did the Medicaid expansions for children displace private insurance? An analysis using the SIPP." Journal of Health Economics (January) 19(1):33-60.

Boardman, Jason D., Robert A. Hummer, Yolanda Padilla, and Daniel Powers. 2002. "Low Birth Weight, Social Factors, and Developmental Outcomes among Children in the United States." Demography. 39: 353-68.

Case, Anne, Angela Fertig and Christina Paxson. 2005. "The Lasting Impact of Childhood Health and Circumstance." Journal of Health Economics, volume 24, pp. 365-389.

Centers for Medicare and Medicaid Services (CMMS). 2004. "State 1998 SCHIP Evaluations and State SCHIP Summaries.” http://www.cms.hhs.gov/schip/researchers/default.asp.

Conley, Dalton and Neil G. Bennett. 2000. "Is Biology Destiny? Birth Weight and Life Chances." American Sociological Review. 65(3): 458-467.

Currie, Janet. 2008. "Healthy, Wealthy, and Wise: Socioeconomic Status, Poor Health in Childhood, and Human Capital Development" NBER Working Paper \#13987.

Currie, Janet, Sandra Decker, and Wanchuan Lin. "Has Public Health Insurance for Older Children Reduced Disparities in Access to Care and Health Outcomes?" Journal of Health Economics. 27(6): 1567-1581.

Currie, Janet and Jonathan Gruber. 1996a. "Health Insurance Eligibility, Utilization of Medical Care, and Child Health." Quarterly Journal of Economics. 111: 431-66.

Currie, Janet and Jonathan Gruber. 1996b. "Saving Babies: The Efficacy and Cost of Recent Expansions of Medicaid Eligibility for Pregnant Women." Journal of Political Economy. 104: 1263-96. 
Currie, Janet and Mark Stabile. 2006. "Child Mental Health and Human Capital Accumulation: The Case of ADHD". Journal of Health Economics. 25(6):1094-1118.

Cutler, David M. and Jonathan Gruber. 1996. "Does Public Insurance Crowd Out Private Insurance?" Quarterly Journal of Economics 111(2): 391-430.

Cutler, David M. and Jonathan Gruber. 1997. "Medicaid and Private Insurance: Evidence and Implications," Health Affairs 16(1):194-200.

Dafny, Leemore and Jonathan Gruber. 2005. "Public Insurance and Child Hospitalizations: Access and Efficiency Effects," Journal of Public Economics 89(1): 109-129.

Dahl, Gordon and Lance Lochner. 2005. "The Impact of Family Income on Child Achievement," NBER Working Paper \#11279.

Diette, Gregory B.; Leona Markson; Elizabeth A. Skinner; Theresa T. H. Nguyen; Pamela Algatt-Bergstrom; and Albert W. Wu. 2000. "Nocturnal Asthma in Children Affects School Attendance, School Performance, and Parents' Work Attendance." Archives of Pediatric and Adolescent Medicine 154: 923-928.

Dubay, Lisa and Genevieve Kenney. 1996. "The Effects of Medicaid Expansions on Insurance Coverage of Children," The Future of Children 6(1):152 - 161.

Dubay, Lisa and Genevieve Kenney. 1997. "Did Medicaid Expansions For Pregnant Women Crowd Out Private Coverage?" Health Affairs 16(1): 185 - 193.

Fowler, Mary Glenn, Marsha G. Davenport and Rekha Garg. 1992. "School Functioning of US Children with Asthma." Pediatrics. 90(6):939-944.

Gortmaker, Steven L., Deborah K. Walker, Michael Weitzman and Arthur M. Sobol. 1990. "Chronic Conditions, Socioeconomic Risks, and Behavioral Problems in Children and Adolescents." Pediatrics 85:267-276.

Gozal, David. 1998. "Sleep-Disordered Breathing and School Performance in Children." Pediatrics 102(3): 616-620.

Gruber, Jonathan. 2003. "Medicaid." in Robert A. Moffitt (ed.), Means-Tested Transfer Programs in the United States.

Gruber, Jonathan and Kosali Simon. 2008. "Crowd-Out Ten Years Later: Have Recent Public Insurance Expansions Crowded Out Private Health Insurance?" Journal of Health Economics March 27(2): 201-217.

Gruber, Jonathan and Aaron Yelowitz. 1999. "Public Health Insurance and Private Savings," Journal of Political Economy 107(6): 1249-1274. 
Ham, John, and Lara Shore Sheppard. 2005 "Did Expanding Medicaid Affect Welfare Participation?" Industrial and Labor Relations Review, vol. 58, no. 3, April, pp. 452-470.

Haveman, Robert and Bobbi Wolfe. 1995. "The Determinants of Children's Attainments: A Review of Methods and Findings." Journal of Economic Literature 33(4): 1829-1878.

Jacob, Brian A. 2005. "Accountability, Incentives and Behavior." Journal of Public Economics. 89(5-6): 761-796.

Joyce, Ted and Andrew Racine. 2003. "Chip Shots: Association Between the State Children's Health Insurance Programs and Immunization Coverage and Delivery." NBER Working Paper \#9831.

Levy, Helen and David Meltzer. 2008. "The Impact of Health Insurance on Health" Annual Review of Public Health 29:399-409.

Lloyd, B.W., K. Wheldall, D. Perks. 1988. "Controlled Study of Intelligence and School Performance of Very Low Birth Weight Children from a Defined Geographical Area." Developmental Medicine and Child Neurology. 30:36-42.

LoSasso, Anthony and Thomas Buchmueller. 2004. "The Effect of the State Children's Health Insurance Program on Health Insurance Coverage." Journal of Health Economics. 23:1059-82.

Mayer, Susan. 1997. What Money Can't Buy: Family Income and Children's Life Chances. Cambridge, MA: Harvard University Press.

Morris, Pamela, Greg Duncan and Christopher Rodrigues. 2004. "Does Money Really Matter? Estimating Impacts of Family Income on Children's Achievement with Data from Random Assignment Experiments," Northwestern University, mimeo.

National Governors Association, Education Policy Studies Division. 2000. Improving Academic Performance by Meeting Student Health Needs. Washington, DC: National Governors Association.

Rossi, Robert and Alesia Montgomery. 2004. Educational Reforms and Students at Risk: A Review of the Current State of the Art. Washington, DC: U.S. Department of Education, Office of Educational Research and Improvement, Office of Research.

Shore-Sheppard, Lara. 2003. "Expanding Public Health Insurance for Children," in Changing Welfare, Rachel Gordon and Herbert Walberg, eds. New York: Kluwer Academic/Plenum Publishers.

Shore-Sheppard, Lara D. 2005. "Stemming the Tide: The Effect of Expanding Medicaid Eligibility on Health Insurance." National Bureau of Economic Research Working Paper 11091. 
Solon, Gary. 1992. "Intergenerational Income Mobility in the United States," American Economic Review. 82(3): 393-408.

Yazici, Esel Y. and Robert Kaestner. 2000. "Medicaid Expansions And The Crowding Out of Private Health Insurance Among Children," Inquiry 37(1):23-32.

Yelowitz, Aaron. 1995. "The Medicaid Notch, Labor Supply and Welfare Participation: Evidence from Eligibility Expansions.” Quarterly Journal of Economics. 110(4): 909-39.

Zimmerman, David J. 1992. "Regression Toward Mediocrity in Economic Stature," American Economic Review. 82(3): 409-429. 
Table 1: Public Health Insurance Eligibility for Minors by State and Year -- Age and Maximum Income

\begin{tabular}{|c|c|c|c|c|c|c|c|c|c|c|c|c|c|c|c|c|c|}
\hline & 1988 & 1989 & 1990 & 1991 & 1992 & 1993 & 1994 & 1995 & 1996 & 1997 & 1998 & 1999 & 2000 & 2001 & 2002 & 2003 & 2004 \\
\hline California & 0 & 0 & $\begin{array}{l}/ 185 \\
4 / 100\end{array}$ & $5 / 133$ & $\begin{array}{l}5 / 133 \\
8 / 100\end{array}$ & $\begin{array}{l}5 / 133 \\
9 / 100\end{array}$ & $\begin{array}{c}5 / 133 \\
10 / 100\end{array}$ & $\begin{array}{c}5 / 133 \\
11 / 100\end{array}$ & $\begin{array}{c}0 / 200 \\
5 / 133 \\
12 / 100\end{array}$ & $\begin{array}{c}0 / 200 \\
5 / 133 \\
13 / 100\end{array}$ & $\begin{array}{c}0 / 200 \\
6 / 133 \\
14 / 100 \\
19 / 82\end{array}$ & $\begin{array}{c}0 / 250 \\
19 / 200\end{array}$ & $19 / 250$ & $19 / 250$ & $19 / 250$ & $\begin{array}{c}0 / 300 \\
19 / 250\end{array}$ & $\begin{array}{c}0 / 300 \\
19 / 250\end{array}$ \\
\hline Texas & 0 & $\begin{array}{l}0 / 130 \\
1 / 100\end{array}$ & $\begin{array}{l}0 / 130 \\
3 / 100\end{array}$ & $5 / 133$ & $\begin{array}{l}5 / 133 \\
8 / 100\end{array}$ & $\begin{array}{l}0 / 185 \\
5 / 133 \\
9 / 100\end{array}$ & $\begin{array}{c}0 / 185 \\
5 / 133 \\
10 / 100\end{array}$ & $\begin{array}{c}0 / 185 \\
5 / 133 \\
11 / 100\end{array}$ & $\begin{array}{c}0 / 185 \\
5 / 133 \\
12 / 100\end{array}$ & $\begin{array}{c}0 / 185 \\
5 / 133 \\
13 / 100\end{array}$ & $\begin{array}{c}0 / 185 \\
6 / 133 \\
14 / 100 \\
19 / 17\end{array}$ & $\begin{array}{c}0 / 185 \\
6 / 133 \\
19 / 100\end{array}$ & $\begin{array}{c}0 / 185 \\
6 / 133 \\
19 / 100\end{array}$ & $19 / 200$ & $19 / 200$ & $19 / 200$ & $19 / 200$ \\
\hline New York & 0 & 0 & $0 / 185$ & $\begin{array}{l}0 / 185 \\
5 / 133\end{array}$ & $12 / 185$ & $12 / 185$ & $\begin{array}{c}0 / 185 \\
12 / 160\end{array}$ & $\begin{array}{c}0 / 185 \\
12 / 160\end{array}$ & $\begin{array}{c}0 / 185 \\
5 / 133 \\
12 / 100\end{array}$ & $\begin{array}{c}0 / 185 \\
5 / 133 \\
13 / 100\end{array}$ & $\begin{array}{c}0 / 185 \\
6 / 133 \\
14 / 100 \\
19 / 87\end{array}$ & $19 / 192$ & 19/192 & 19/192 & $19 / 250$ & $19 / 250$ & $19 / 250$ \\
\hline Florida & $1 / 100$ & $4 / 100$ & $\begin{array}{l}0 / 150 \\
5 / 100\end{array}$ & $\begin{array}{l}5 / 133 \\
6 / 100\end{array}$ & $\begin{array}{l}5 / 133 \\
8 / 100\end{array}$ & $\begin{array}{l}5 / 133 \\
9 / 100\end{array}$ & $\begin{array}{c}5 / 133 \\
10 / 100\end{array}$ & $\begin{array}{c}5 / 133 \\
11 / 100\end{array}$ & $\begin{array}{c}0 / 185 \\
5 / 133 \\
18 / 100\end{array}$ & $\begin{array}{c}0 / 185 \\
5 / 133 \\
18 / 100\end{array}$ & $\begin{array}{c}0 / 185 \\
6 / 133 \\
14 / 100 \\
19 / 28\end{array}$ & $19 / 200$ & $19 / 200$ & $19 / 200$ & $19 / 200$ & $19 / 200$ & $19 / 200$ \\
\hline Illinois & 0 & $0 / 100$ & $0 / 100$ & $5 / 133$ & $\begin{array}{l}5 / 133 \\
8 / 100\end{array}$ & $\begin{array}{l}5 / 133 \\
9 / 100\end{array}$ & $\begin{array}{c}5 / 133 \\
10 / 100\end{array}$ & $\begin{array}{c}5 / 133 \\
11 / 100\end{array}$ & $\begin{array}{c}5 / 133 \\
12 / 100\end{array}$ & $\begin{array}{c}5 / 133 \\
13 / 100\end{array}$ & $\begin{array}{c}6 / 133 \\
14 / 100 \\
19 / 46\end{array}$ & $\begin{array}{c}0 / 200 \\
19 / 185\end{array}$ & $\begin{array}{c}0 / 200 \\
19 / 185\end{array}$ & $\begin{array}{c}0 / 200 \\
19 / 185\end{array}$ & $\begin{array}{c}0 / 200 \\
19 / 185\end{array}$ & $\begin{array}{c}0 / 200 \\
19 / 185\end{array}$ & $19 / 200$ \\
\hline
\end{tabular}

Notes: Entries in table show maximum age of eligibility, then maximum income as a percentage of the poverty line. For simplicity, eligibility is as of January of calendar year.

Sources: Yelowitz (1995), Shore-Sheppard (2002), and CMMS (2004). 
Table 2: Public Health Insurance Eligibility for Children with Family Income at 120 Percent of the Poverty Line by Selected State and Age

\begin{tabular}{|c|c|c|c|c|c|}
\hline \multirow{2}{*}{$\begin{array}{l}\text { State and } \\
\text { Birth Year }\end{array}$} & \multicolumn{3}{|c|}{ covered at age: } & \multicolumn{2}{|c|}{ years covered by age } \\
\hline & 0 & 9 & 13 & 9 & 13 \\
\hline \multicolumn{6}{|l|}{ California } \\
\hline 1986 & no & no & yes & 1 & 2 \\
\hline 1988 & no & no & yes & 3 & 6 \\
\hline 1990 & yes & yes & yes & 7 & 11 \\
\hline \multicolumn{6}{|l|}{ Texas } \\
\hline 1986 & no & no & yes & 1 & 2 \\
\hline 1988 & no & no & yes & 3 & 6 \\
\hline 1990 & yes & no & yes & 6 & 9 \\
\hline \multicolumn{6}{|l|}{ New York } \\
\hline 1986 & no & yes & yes & 5 & 6 \\
\hline 1988 & no & no & yes & 5 & 8 \\
\hline 1990 & Yes & yes & yes & 7 & 11 \\
\hline \multicolumn{6}{|l|}{ Florida } \\
\hline 1986 & no & no & yes & 1 & 2 \\
\hline 1988 & no & no & yes & 3 & 6 \\
\hline 1990 & yes & yes & yes & 7 & 11 \\
\hline \multicolumn{6}{|l|}{ Illinois } \\
\hline 1986 & no & no & yes & 1 & 2 \\
\hline 1988 & no & no & yes & 3 & 6 \\
\hline 1990 & no & yes & yes & 6 & 10 \\
\hline
\end{tabular}

Note: This table reflects eligibility for a child born in January of the given year. 
Table 3: Impact of Medicaid/SCHIP Expansions on NAEP Test Scores

\begin{tabular}{|c|c|c|c|c|c|c|}
\hline & $\begin{array}{c}4^{\text {th }} \text { Grade } \\
\text { Reading } \\
\text { Scores } \\
(1) \\
\end{array}$ & $\begin{array}{c}8^{\text {th }} \text { Grade } \\
\text { Reading } \\
\text { Scores } \\
(2) \\
\end{array}$ & $\begin{array}{c}\text { Difference in } \\
\text { Reading Scores } \\
\text { (3) }\end{array}$ & $\begin{array}{c}4^{\text {th }} \text { Grade Math } \\
\text { Scores } \\
(4)\end{array}$ & $\begin{array}{c}8^{\text {th }} \text { Grade Math } \\
\text { Scores } \\
(5)\end{array}$ & $\begin{array}{c}\text { Difference in } \\
\text { Math Scores } \\
(6)\end{array}$ \\
\hline $\begin{array}{l}\text { Percentage eligible in } \\
\text { in student's year of birth }\end{array}$ & $\begin{array}{c}2.138 \\
(3.641)\end{array}$ & $\begin{array}{c}1.049 \\
(4.854)\end{array}$ & $\begin{array}{c}5.815 \\
(2.365)\end{array}$ & $\begin{array}{c}0.844 \\
(4.102)\end{array}$ & $\begin{array}{c}2.384 \\
(4.446)\end{array}$ & $\begin{array}{l}-1.629 \\
(2.265)\end{array}$ \\
\hline $\begin{array}{l}\text { Mean Percentage of Life } \\
\text { Eligible since birth }\end{array}$ & $\begin{array}{l}-7.833 \\
(8.104)\end{array}$ & $\begin{array}{l}-18.453 \\
(12.168)\end{array}$ & $\begin{array}{c}-5.177 \\
(13.979)\end{array}$ & $\begin{array}{l}-12.723 \\
(8.159)\end{array}$ & $\begin{array}{l}-3.298 \\
(9.708)\end{array}$ & $\begin{array}{c}-0.709 \\
(10.476)\end{array}$ \\
\hline $\begin{array}{l}\text { Percentage Currently } \\
\text { Eligible }\end{array}$ & $\begin{array}{l}3.318 \\
(4.272)\end{array}$ & $\begin{array}{c}4.926 \\
(5.826)\end{array}$ & $\begin{array}{c}9.583 \\
(28.148)\end{array}$ & $\begin{array}{l}3.838 \\
(3.384)\end{array}$ & $\begin{array}{c}2.1 \\
(2.778)\end{array}$ & $\begin{array}{c}2.186 \\
(3.093)\end{array}$ \\
\hline Sample Size & 262 & 169 & 169 & 227 & 261 & 223 \\
\hline
\end{tabular}

Notes: Regressions are based on aggregated state/year NAEP test score data and simulated Medicaid eligibility measures by state in students' state/year of residence. In models where the outcome is the difference in scores between the two grades, the eligibility measures are calculated as the difference in rates between the two birth cohorts. Additional explanatory variables in "undifferenced" models include the unemployment rate, the percentage of the population that is married, the percentage white, the percentage who have dropped out of high school, are high school graduates, and have attended some college, and the percentage of the state's population that is $0-4,5-17,18-24,25-44,45-64$, and $65+$. Standard errors are clustered at the state level. Regressions are unweighted. 
Table 4: Impact of Medicaid/SCHIP Expansions on Infant Health

\begin{tabular}{|c|c|c|c|c|c|c|}
\hline & $\begin{array}{l}\text { All Mothers } \\
\text { (Full Sample) } \\
(1)\end{array}$ & $\begin{array}{c}\text { All Mothers } \\
\text { (Restricted Sample) } \\
\text { (2) }\end{array}$ & $\begin{array}{c}\text { Mothers with Less } \\
\text { than HS Degree } \\
\text { (3) }\end{array}$ & $\begin{array}{l}\text { Mothers with HS } \\
\text { Degree } \\
(4)\end{array}$ & $\begin{array}{c}\text { Mothers with Some } \\
\text { College } \\
(5)\end{array}$ & $\begin{array}{l}\text { Mothers with } \\
\text { College Degree } \\
(6)\end{array}$ \\
\hline & \multicolumn{6}{|c|}{ Low Birth Weight } \\
\hline $\begin{array}{l}\text { Percentage of Cohort } \\
\text { Eligible at Birth (x100) }\end{array}$ & $\begin{array}{l}-0.298 \\
(0.138)\end{array}$ & --- & $\begin{array}{l}-0.985 \\
(0.390)\end{array}$ & $\begin{array}{l}-0.784 \\
(0.420)\end{array}$ & $\begin{array}{l}-0.693 \\
(0.384)\end{array}$ & $\begin{array}{l}-0.311 \\
(0.233)\end{array}$ \\
\hline \multirow[t]{2}{*}{ Sample Size } & $\begin{array}{l}7.267 \\
1,020\end{array}$ & --- & $\begin{array}{l}9.173 \\
1,020\end{array}$ & $\begin{array}{l}7.580 \\
1,020\end{array}$ & $\begin{array}{l}6.527 \\
1,020\end{array}$ & $\begin{array}{l}5.598 \\
1,020\end{array}$ \\
\hline & \multicolumn{6}{|c|}{ Infant Mortality Rate } \\
\hline $\begin{array}{l}\text { Percentage of Cohort } \\
\text { Eligible at Birth }(\mathrm{x} 100)\end{array}$ & $\begin{array}{l}-0.036 \\
(0.029)\end{array}$ & $\begin{array}{l}-0.017 \\
(0.054)\end{array}$ & $\begin{array}{l}-0.137 \\
(0.113)\end{array}$ & $\begin{array}{l}-0.146 \\
(0.088)\end{array}$ & $\begin{array}{l}-0.071 \\
(0.080)\end{array}$ & $\begin{array}{l}-0.030 \\
(0.053)\end{array}$ \\
\hline $\begin{array}{l}\text { Mean Rate (x100) } \\
\text { Sample Size }\end{array}$ & $\begin{array}{l}0.847 \\
1,020\end{array}$ & $\begin{array}{c}0.845 \\
765\end{array}$ & $\begin{array}{c}1.118 \\
765\end{array}$ & $\begin{array}{c}0.867 \\
765\end{array}$ & $\begin{array}{c}0.681 \\
765\end{array}$ & $\begin{array}{c}0.509 \\
765\end{array}$ \\
\hline
\end{tabular}

Notes: Infant mortality regressions include a "full sample," obtained from published reports on aggregate state/year infant mortality rates and a "restricted sample," where aggregate rates were calculated from linked birth/infant death Vital Statistics microdata. All birth weight data was calculated from Vital Statistics Natality microdata. All models include state and year fixed effects along with state-specific linear trends. Additional explanatory variables include the unemployment rate, the percentage of the population that is married, the percentage white, the percentage who have dropped out of high school, are high school graduates, and have attended some college, and the percentage of the state's population that is $0-4,5-17,18-24,25-44,45-64$, and $65+$. Standard errors are clustered at the state level. Regressions are weighted by the number of births in the state/year. 
Table 5: Impact of Health Status at Birth on NAEP Test Scores

\begin{tabular}{|c|c|c|c|c|c|c|}
\hline & $\begin{array}{c}4^{\text {th }} \text { Grade } \\
\text { Reading Scores } \\
(1)\end{array}$ & $\begin{array}{c}8^{\text {th }} \text { Grade } \\
\text { Reading Scores } \\
(2) \\
\end{array}$ & $\begin{array}{c}\text { Difference in } \\
\text { Reading Scores } \\
(3) \\
\end{array}$ & $\begin{array}{c}4^{\text {th }} \text { Grade Math } \\
\text { Scores } \\
(4) \\
\end{array}$ & $\begin{array}{c}8^{\text {th }} \text { Grade Math } \\
\text { Scores } \\
(5) \\
\end{array}$ & $\begin{array}{c}\text { Difference in } \\
\text { Math Scores } \\
(6) \\
\end{array}$ \\
\hline \multicolumn{7}{|l|}{ Mean of Dependent } \\
\hline Variable & 215.9 & 261.5 & -45.1 & 227.5 & 271.3 & -45.2 \\
\hline \multirow[t]{2}{*}{ Sample Size } & 262 & 169 & 169 & 227 & 261 & 223 \\
\hline & \multicolumn{6}{|c|}{ Infant Mortality Rate } \\
\hline \multirow[t]{2}{*}{$\begin{array}{l}\text { Rate per } 1,000 \text { births } \\
\text { in student's year of birth }\end{array}$} & $\begin{array}{l}-10.857 \\
(3.478)\end{array}$ & $\begin{array}{l}-9.583 \\
(4.654)\end{array}$ & $\begin{array}{l}-4.868 \\
(2.240)\end{array}$ & $\begin{array}{l}-7.853 \\
(3.030)\end{array}$ & $\begin{array}{l}-4.814 \\
(3.185)\end{array}$ & $\begin{array}{l}-1.166 \\
(1.195)\end{array}$ \\
\hline & \multicolumn{6}{|c|}{ Rate of Low Birth Weight } \\
\hline $\begin{array}{l}\text { Rate per } 100 \text { births } \\
\text { in student's year of birth }\end{array}$ & $\begin{array}{l}-0.266 \\
(0.656) \\
\end{array}$ & $\begin{array}{r}0.687 \\
(0.564) \\
\end{array}$ & $\begin{array}{l}-1.058 \\
(0.325) \\
\end{array}$ & $\begin{array}{c}0.928 \\
(1.040) \\
\end{array}$ & $\begin{array}{r}0.839 \\
(0.767) \\
\end{array}$ & $\begin{array}{r}0.277 \\
(0.419) \\
\end{array}$ \\
\hline
\end{tabular}

Notes: Regressions are based on aggregated state/year NAEP test score data and Vital Statistics data on rates of infant mortality rate and low birth weight by state in students' state/year of birth. In models where the outcome is the difference in scores between the two grades, the infant mortality rate and the rate of low birth weight are measured as the difference in rates between the two birth cohorts. Additional explanatory variables in "undifferenced" models include the unemployment rate, the percentage of the population that is married, the percentage white, the percentage who have dropped out of high school, are high school graduates, and have attended some college, and the percentage of the state's population that is $0-4,5-17,18-24,25-44,45-64$, and $65+$. All models include state and year fixed effects. Standard errors are clustered at the state level. Regressions are unweighted. 
Figure 1A: Trends in Children's Eligibility for Public Health Insurance

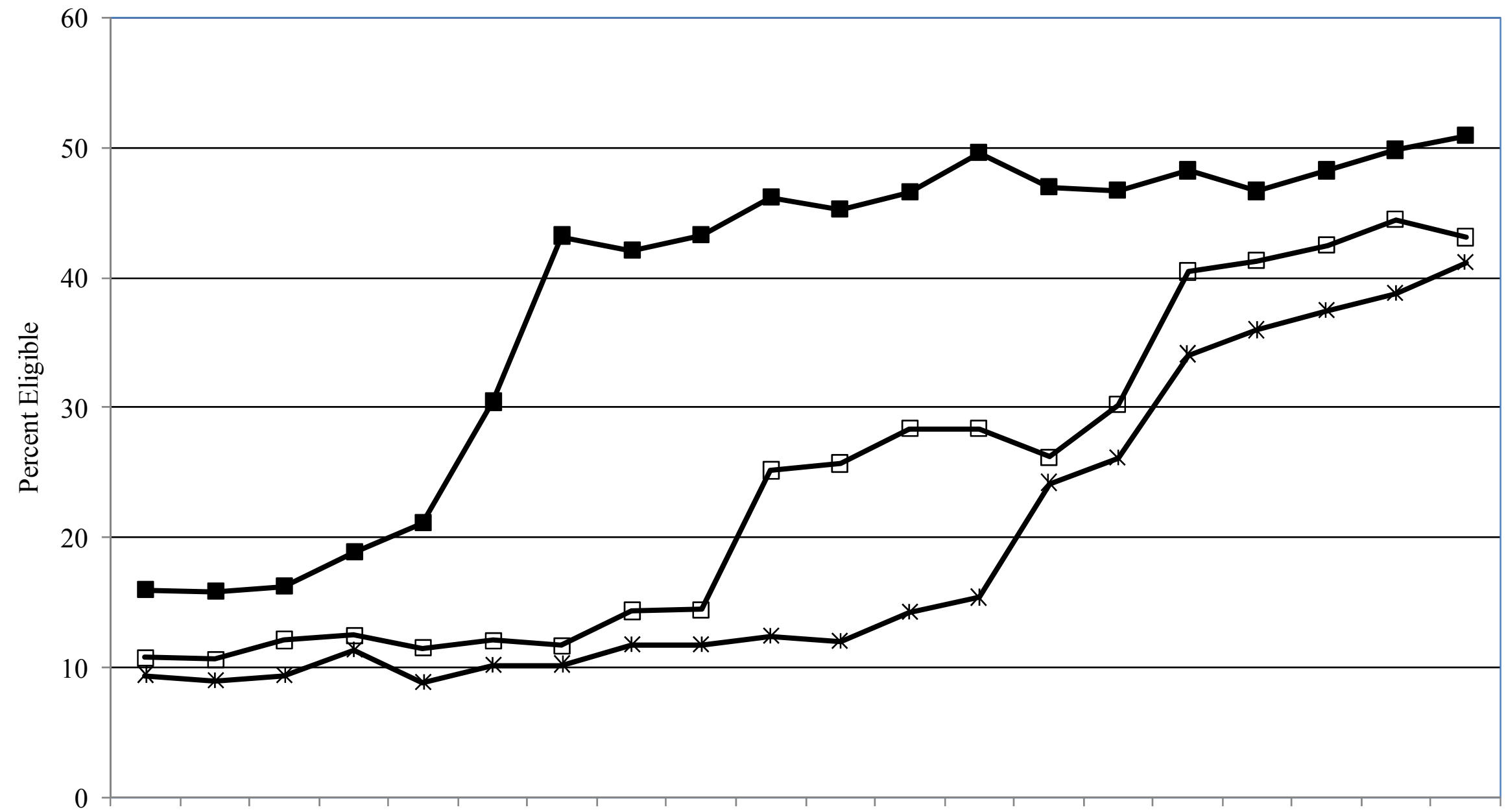

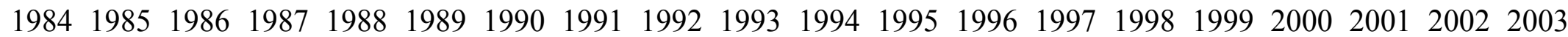
Year

$\rightarrow$ Eligible at Birth $\quad$ Eligible at Age $9 \quad *$ Eligible at Age 13 


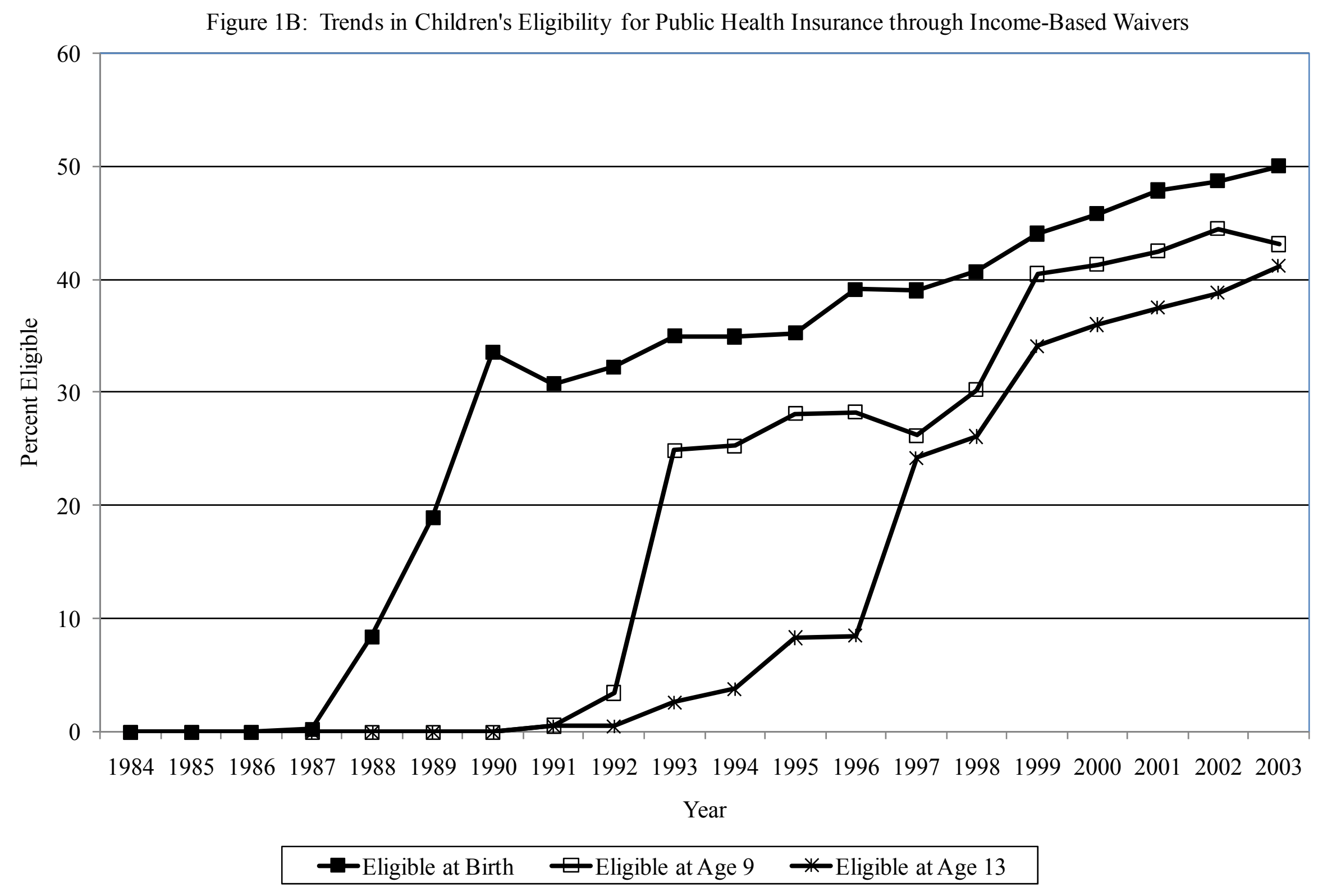


Figure 2: Variation across States in Percentage Medicaid Eligible at Birth

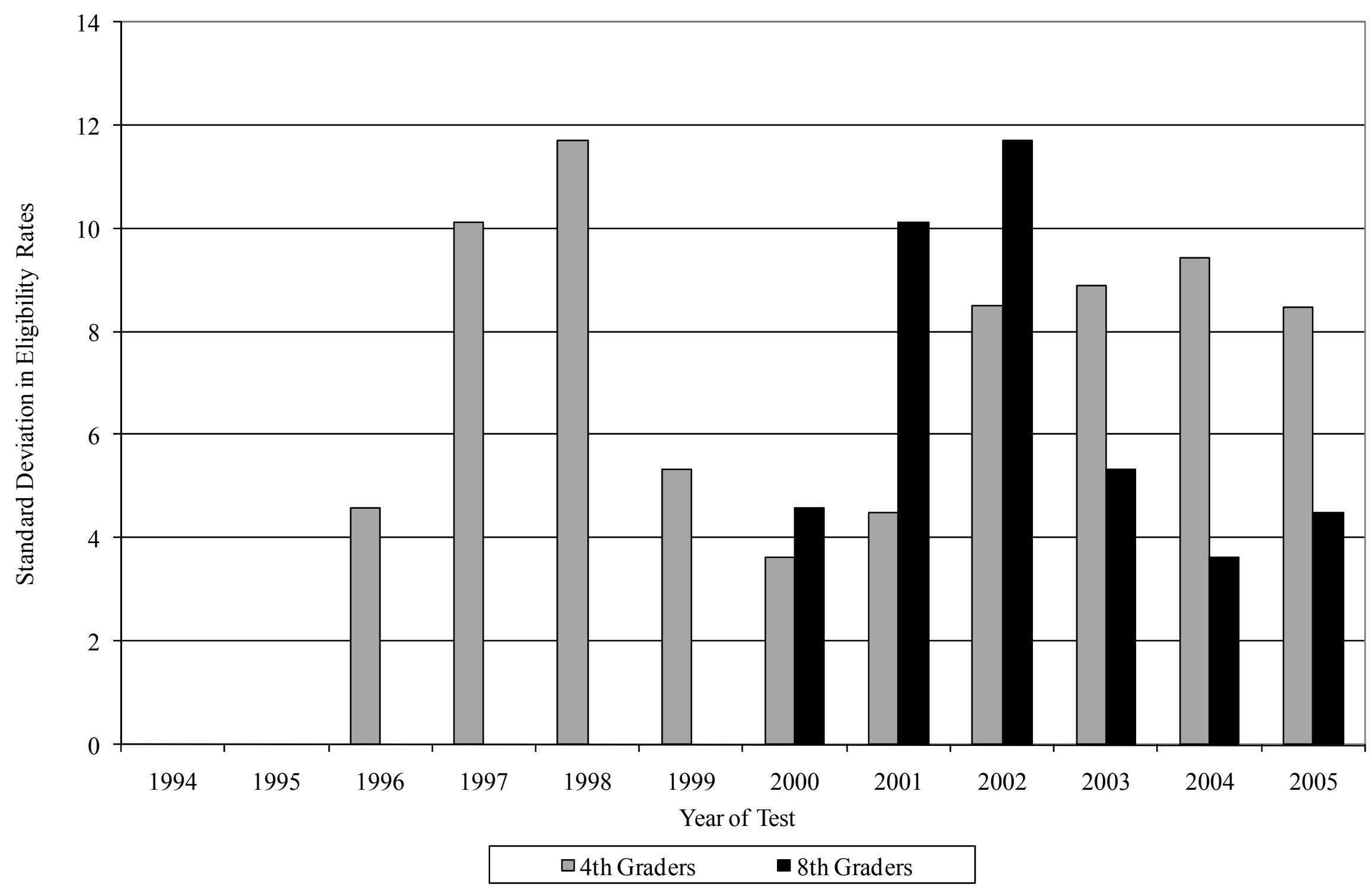


Figure 3: Variation across States in Percentage Currently Medicaid Eligible

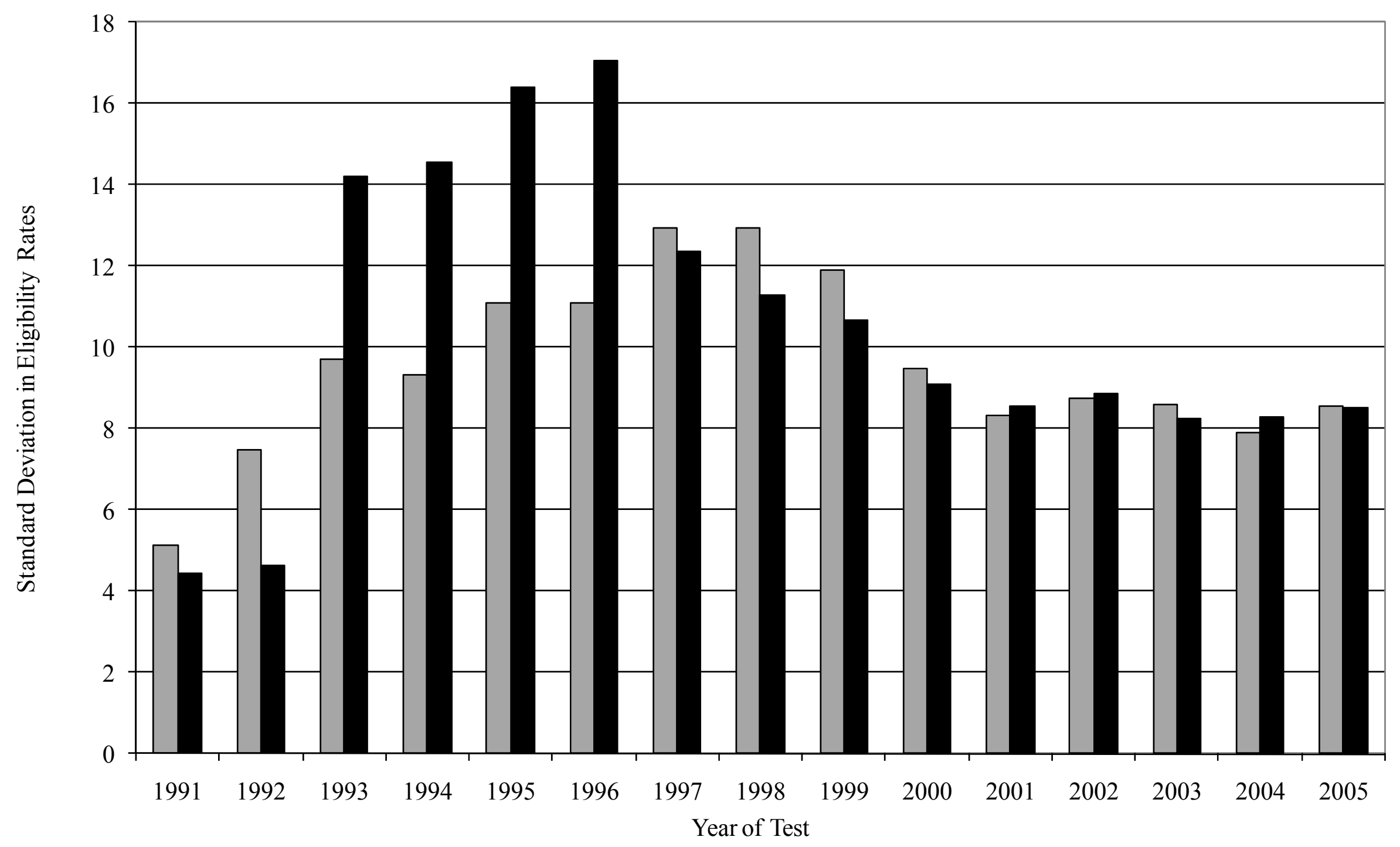

$\square$ 4th Graders

- 8th Graders 